\title{
Adsorption of heavy metals and methylene blue from aqueous solution with citric acid modified peach stone
}

\author{
Junhua Yan ${ }^{a, b}$, Guihong Lan ${ }^{a, c^{*}}$, Haiyan Qiu ${ }^{* * *}$, Chao Chen ${ }^{a}$, Yongqiang Liu ${ }^{d}$, \\ Guoyong $\mathrm{Du}^{a}$, Jihong Zhang ${ }^{e}$ \\ ${ }^{a}$ College of Chemistry and Chemical Engineering, Southwest Petroleum University, \\ Chengdu 610500, China \\ ${ }^{b}$ Sichuan Xinda Enterprise Group Co., Ltd \\ ${ }^{c}$ College of Architecture and Environment, Sichuan University, 610065 Chengdu, \\ China \\ ${ }^{d}$ Faculty of Engineering and the Environment, University of Southampton, \\ Southampton SO171BJ, United Kingdom \\ ${ }^{e}$ Xinjiang oil field No. 1 gas plant \\ ${ }^{*}$ Co-first author \\ ${ }^{* *}$ Corresponding author.E-mail:haiyanqiu316@sina.com
}

\begin{abstract}
Peach stones (PS) modified by citric acid (MPS) were used to remove heavy metals and methylene blue (MB) from wastewater. The effects of experimental factors such as $\mathrm{pH}$, adsorbent dosage and contact time, etc were conducted. Moreover, the adsorption kinetics and isotherm studies also were investigated. According to the Langmuir isotherm model, the maximum adsorption capacities of $\mathrm{Pb}^{2+}, \mathrm{Cd}^{2+}, \mathrm{Cu}^{2+}$ and MB were 118.76, 37.48, 32.22 and $178.25 \mathrm{mg} / \mathrm{g}$, respectively. Finally, column experiments were also carried out to investigate the adsorption of $\mathrm{Pb}^{2+}$ and $\mathrm{MB}$. All
\end{abstract}


results indicated that peach stone has a good potential for the treatment of wastewater.

Keywords: Peach stone; Modification; Adsorption; Heavy metals; Methylene blue

\section{Introduction}

Environmental pollution caused by anthropogenic activities has drawn extensive attention. For example, wastewater produced from printing, leather tanning, textile and paper industries ${ }^{[1,2]}$ contains a large amount of metal ions and dyes causing serious problems to the entire biosphere, even at low concentrations. Heavy metals and dyes are toxic and have even serious detrimental effects to human through the food chain. Heavy metals are insusceptible to be biodegradable and easily accumulate in living organisms, leading to physical and mental diseases ${ }^{[3]}$. As to dyestuffs, the dyes present in wastewater can inhibit photosynthetic activity of aquatic life by preventing sunlight penetration and even can degrade into harmful compounds to threat life health ${ }^{[4,5]}$. To minimize harm from the effluents containing heavy metals and dyes before discharging into environment, various treatment measures such as chemical precipitation, flocculation, membrane filtration, adsorption and so on have been employed to deal with them ${ }^{[6-8]}$. Among these methods, adsorption is believed to be a very promising and feasible method compared with conventional treatments due to its high efficiency and low costs. At present, a large number of adsorption materials with high adsorption capacity such as activated carbon, graphene and nanofilm have been widely researched. However, their costs of preparation and regeneration are high so that the low-cost materials are in demand. 
Lignocellulosic agricultural by-products and waste materials containing a variety of functional groups such as carboxyl, hydroxyl and amine groups are abundant and cheap, which could be used to adsorb contaminants from wastewater. Considering the easy availability and low cost, great attention has been paid to use lignocellulosic wastes to remove heavy metals and dyes ${ }^{[9]}$. In recent years, various kinds of agricultural residues and by-products such as wheat bran ${ }^{[10]}$, rice husk ${ }^{[11]}$, wheat straw ${ }^{[12]}$, soybean meal waste ${ }^{[13]}$ and Alternanthera philoxeroides ${ }^{[14]}$ have been widely investigated for wastewater treatment. However, the treatment efficiency by natural materials without any modification is not high enough for real application, so that more and more studies are being carried out to improve their adsorption capacity. To enhance the adsorption capacity of contaminants from aqueous solutions, chemical modification by $\mathrm{HCl}$, $\mathrm{NaOH}$, citric acid and polyethylenimine to introduce more active functional groups has been investigated ${ }^{[15,16]}$. Nowadays, citric acid as a good modificator has been used to increase the contents of carboxyl group through esterification reaction ${ }^{[17]}$. Meanwhile, some literatures have reported that agricultural materials such as barley straw ${ }^{[18]}$, corncob $^{[19]}$ and pine sawdust ${ }^{[20]}$ modified with citric acid had excellent adsorption efficiency for heavy metals and MB.

Peach (Prunus persica) is a kind of popular and abundant fruit in summer in Sichuan province in China, which causes the difficulty of disposal of peach stones (PS). Because of the similar constituents of peach stone with most agricultural by-products, it is expected that PS could be employed to treat wastewater. Peach stones have been directly used as an adsorbent to adsorb lead and copper, but the adsorption capacity of 
lead and copper was not high ${ }^{[21,22]}$. Furthermore, peach stones have also been utilized as raw materials to prepare activated carbon to remove heavy metals from effluent ${ }^{[23,}$ ${ }^{24]}$. Nevertheless, the processing cost of activated carbon technology is expensive.

In this paper, PS were firstly chose as raw materials and modified by citric acid to prepare adsorbent MPS, and also were firstly used to remove heavy metals $\left(\mathrm{Cd}^{2+}, \mathrm{Cu}^{2+}\right.$, $\mathrm{Pb}^{2+}$ ) and MB from wastewater compared with literatures reported. Meanwhile, it's very helpful to realize resource recycling use and it also avoided peach PS being casually discarded. At first, the feasibility of MPS for heavy metals and MB was assessed by investigating the effects of $\mathrm{pH}$, dosage, contact time, initial concentration. And to evaluate kinetic model and isotherm model, experimental data was fitted with pseudosecond order and intra-particle diffusion kinetic models, the Langmuir isotherm model and Fredunlich isotherm model, respectively. Moreover, metal binding mechanisms by MPS was investigated by being characterized with elemental analyzer, Fourier transformed infrared spectroscopy (FTIR), scanning electron microscopy (SEM), surface area analyzer and thermogravimetric analysis (TGA). Finally, column experiments were investigated to stimulate the adsorption of $\mathrm{Pb}^{2+}$ and $\mathrm{MB}$.

\section{Materials and Methods}

\subsection{Materials}

Peach stones were obtained from Longquan district, Chengdu, China. Citric acid (CA), copper nitrate, cadmium nitrate, lead nitrate, sodium hydroxide and methylene blue (MB) were purchased from Kelong chemical reagent factory (Chengdu, China). 
All reagents were of analytical grade and deionized water was used in all experiments. And all experiments were carried out three times.

\subsection{Preparation of adsorbent MPS}

\subsubsection{Chemical modifications of peach stones with critic acid}

Peach stones were firstly washed by deionized water to remove dust and other impurities, and dried in an oven for $24 \mathrm{~h}$ at $90^{\circ} \mathrm{C}$. Then these dried peach stones were milled and sieved to obtain 50-60 mesh fractions (labeled as PS). To increase the proportion of active surfaces and to inhibit tannin compounds [20], twenty grams of sieved peach stones were soaked in $400 \mathrm{ml}$ of $0.1 \mathrm{M} \mathrm{NaOH}$ and stirred in a magnetic stirrer for $1 \mathrm{~h}$ at room temperature. Then the soaked peach stones were rinsed several times with deionized water to remove excess base until the $\mathrm{pH}$ reached approximately to neutral, dried overnight at $50^{\circ} \mathrm{C}$ in the oven (labeled as BPS) and stored in plastic bags for the following experiments.

Modification experiment of peach stones with critic acid was carried out according to the literatures reported in previous years ${ }^{[25,26]}$. Firstly, the dry samples (BPS) were mixed with $0.8 \mathrm{M}$ CA (optimum concentration) in a ratio of $1.0 \mathrm{~g}$ base-peach stones to $12.5 \mathrm{ml} \mathrm{CA}$ and stirred in a magnetic stirrer for $2 \mathrm{~h}$ at $300 \mathrm{rmp}$ at room temperature. Next, the samples were poured into a stainless steel tray and dried at $50^{\circ} \mathrm{C}$ in an oven for $24 \mathrm{~h}$. Afterward, the dry samples were reacted for $4 \mathrm{~h}$ (optimum time) at $120^{\circ} \mathrm{C}$ (optimum temperature) in an oven. The modification conditions were optimized by varying concentrations of critic acid (0.2-1 M), reaction times (1-5 h) and reaction 
temperature $\left(100-150^{\circ} \mathrm{C}\right)$. Finally, the products were soaked in deionized water for $1 \mathrm{~h}$ and washed repeatedly until there was no turbidity when $10 \mathrm{ml}$ of $0.1 \mathrm{M}$ lead nitrate was added. The final reaction products were dried overnight in an oven at $50^{\circ} \mathrm{C}$ (labeled as MPS).

\subsubsection{Carboxyl determination}

A dry sample $(0.2 \mathrm{~g})$ was slurried in water and $0.1 \mathrm{M} \mathrm{NaOH}$ was added. After being stirred for $24 \mathrm{~h}$, the mixture was back-titrated with $0.1 \mathrm{M} \mathrm{HCl}$ to the phenolphthalein end point. Meanwhile, conversion factors were determined using citric acid as standards. PS was used as a control.

\subsection{Adsorbent characterization}

The $\mathrm{C}, \mathrm{H}$ and $\mathrm{N}$ contents of the materials before and after modification were obtained by a CHN Elemental Analyzer (Var10EL-III, Germany). The changes of functional groups on the materials before and after modification and adsorption of heavy metals and MB were determined by FTIR spectrometer (WQF520, China). Surface morphology of the samples was characterized using scanning electron microscopy (SEM, JSM-7500F) at $10.0 \mathrm{kV}$. Surface areas of the samples were analyzed by surface area analyzer (ST-MP-9, US) using Brunauer-Emmett-Teller (BET) method. Thermal gravity analysis (TGA) of the materials before and after modification were determined using a TG instrument (NETZSCH STA 449F3) under air atmosphere scanned from 40 to $800^{\circ} \mathrm{C}$.

\subsection{Preparation of different heavy metal and MB solutions}


Copper nitrate, cadmium nitrate, lead nitrate and MB were dissolved in deionized water to attain stock solutions of $1000 \mathrm{mg} / \mathrm{L} \mathrm{Cu}^{2+}, \mathrm{Cd}^{2+}, \mathrm{Pb}^{2+}$ and $\mathrm{MB}$ and then diluted to different initial concentrations according to the experimental requirements. The solutions containing heavy metal ions before and after adsorption were determined by flame atomic absorption spectrophotometry (FAAS, AA-7020, Beijing, China). MB was analyzed by UV-Vis spectrophotometer (V-1800, Mapada) at the maximum wavelength (665 nm), and the standard curve of $\mathrm{MB}$ was fitted according to the experimental data and was shown in Fig.1.

Fig. 1 Standard curve of MB

\subsection{Adsorption studies}

All adsorption experiments were conducted by adding 0.2 g MPS into $50 \mathrm{ml} 200$ mg/L solutions containing $\mathrm{Cu}^{2+}, \mathrm{Pb}^{2+}, \mathrm{Cd}^{2+}$ and $\mathrm{MB}$ respectively at $30 \pm 2^{\circ} \mathrm{C}$ and shaken at 250 rpm on a constant temperature shaker (QYC-200, Chengdu, China). The solution pH was adjusted by $0.1 \mathrm{M} \mathrm{HCl}$ and $0.1 \mathrm{M} \mathrm{NaOH}$. And the samples were collected at suitable time intervals for 300 min. Then the solutions containing $\mathrm{Cu}^{2+}, \mathrm{Pb}^{2+}$ and $\mathrm{Cd}^{2+}$ were determined by FAAS. The concentrations of MB solutions were determined by UV-Vis spectrophotometer.

The adsorption capacity ( $q_{e} \mathrm{mg} / \mathrm{g}$ ) and removal rate (w \%) were calculated according to the following equations,

$$
q_{e}=\frac{\left(C_{0}-C_{e}\right) V}{m}
$$




$$
w=\frac{C_{0}-C_{e}}{C_{0}} \times 100 \%
$$

Where $q_{e}$ and $\mathrm{w}$ are the uptake amount $(\mathrm{mg} / \mathrm{g})$ and the removal rate (\%) at equilibrium, respectively. $C_{0}$ and $C_{e}$ are the initial and equilibrium concentrations of heavy metals and MB (mg/L), respectively. $\mathrm{m}$ is the mass of adsorbent.

\subsubsection{Effect of adsorbent dosage}

The effects of adsorbent dosage on the adsorption capacity of $\mathrm{Cu}^{2+}, \mathrm{Pb}^{2+}, \mathrm{Cd}^{2+}$ and MB were investigated by adding different amounts of MPS (0.05, 0.1, 0.2, 0.3, 0.4 and $0.5 \mathrm{~g})$ to $50 \mathrm{ml} 200 \mathrm{mg} / \mathrm{L}$ solutions containing different heavy metals and MB, respectively. After adsorption, the solutions were withdrawn to analyze their concentrations according to section 2.4.

\subsubsection{Effect of initial $\mathrm{pH}$}

Batch experiments were carried out in the $\mathrm{pH}$ ranges of 2-7 to investigate the influence of $\mathrm{pH}$ on adsorption of $\mathrm{Cu}^{2+}, \mathrm{Pb}^{2+}, \mathrm{Cd}^{2+}$ and $\mathrm{MB}$. The $\mathrm{pH}$ was adjusted by 0.1 $\mathrm{M} \mathrm{HCl}$ and $0.1 \mathrm{M} \mathrm{NaOH}$.

\subsubsection{Adsorption kinetic studies}

To investigate adsorption kinetics of MPS on heavy metals and MB, adsorption experiments were performed by mixing 0.6 g MPS with $150 \mathrm{ml} 200 \mathrm{mg} / \mathrm{L}$ solution containing $\mathrm{Cu}^{2+}, \mathrm{Pb}^{2+}, \mathrm{Cd}^{2+}$ and $\mathrm{MB}$ respectively. Samples were withdrawn at different time intervals ranging from 10 to $300 \mathrm{~min}$ and the concentrations of solution were analyzed according to section 2.4 . 


\subsubsection{Adsorption isotherm studies}

Adsorption isotherms were carried out by adding $0.2 \mathrm{~g}$ MPS into $50 \mathrm{ml}$ solution containing $\mathrm{Cu}^{2+}, \mathrm{Pb}^{2+}, \mathrm{Cd}^{2+}$ and $\mathrm{MB}$ respectively with different concentrations varying from 50 to $1000 \mathrm{mg} / \mathrm{L}$. And the solutions before and after adsorption by MPS were determined by the above-mentioned methods.

\subsection{Column adsorption studies}

Column experiments of $\mathrm{Pb}^{2+}$ and $\mathrm{MB}$ were performed in a glass column with 0.4 cm internal diameter and $15.0 \mathrm{~cm}$ length. MPS were packed with the bed height of 5.0 $\mathrm{cm}, 6.0 \mathrm{~cm}$ and $7.0 \mathrm{~cm}$, respectively. The initial concentrations of $\mathrm{Pb}^{2+}$ and $\mathrm{MB}$ were $200 \mathrm{mg} / \mathrm{L}$ diluted by the stock solutions of $1000 \mathrm{mg} / \mathrm{l}$ of $\mathrm{Pb}^{2+}$ and $\mathrm{MB}$, respectively. The $\mathrm{pH}$ values of $\mathrm{Pb}^{2+}$ and $\mathrm{MB}$ were 5.0 and 6.0 adjusted by $0.1 \mathrm{M} \mathrm{HCl}$ and $0.1 \mathrm{M} \mathrm{NaOH}$, respectively. And the solutions were pumped up-flow through the fix-bed column at a flow rate of $3.8 \mathrm{ml} / \mathrm{min}$. Samples were collected at various time intervals and the concentrations of samples were analyzed according to section 2.4.

\section{Results and Discussion}

\subsection{Effects of experimental conditions on modification}

In order to determine the optimum concentration of critic acid, reaction time and temperature, batch modification experiments were carried out at various concentrations of CA $(0.2-1 \mathrm{M})$, reaction time $(1-5 \mathrm{~h})$ and reaction temperature $\left(100-150^{\circ} \mathrm{C}\right)$. The final samples were determined by estimating the carboxyl contents to obtain the optimum modification conditions. The modification mechanism was illustrated in Fig. 2. 
Fig. 2 Esterification reaction of peach stone cellulose and critic acid

The carboxyl contents at different concentrations of critic acid, reaction time and temperature are summarized in Table 1 . As shown in Table 1 (a), the carboxyl contents increased with the increase of concentrations of critic acid and reached the maximum at $0.8 \mathrm{M}$, and then decreased. In Table 1 (b) and Table 1 (c), with the increase of reaction time and temperature, the carboxyl contents reached the maximum at $4 \mathrm{~h}$ and $120^{\circ} \mathrm{C}$, respectively. Consequently, $0.8 \mathrm{M}$ critic acid, $4 \mathrm{~h}$ and $120^{\circ} \mathrm{C}$ were chosen as the optimum modification condition with $0.00544 \mathrm{~mol} / \mathrm{g}$ free carboxyl groups on MPS. All samples were prepared at the optimum conditions for the next adsorption experiments.

Table 1 Effect of the concentration of citric acid, reaction time and temperature on citric acid

$$
\text { (CA) and peach stone (PS) reaction. }
$$

\subsection{Adsorbent characterization}

\subsubsection{Elemental analyses of PS and MPS}

As known, PS are mainly composed of cellulose, hemicelluloses and lignin so that it's feasible for modifying PS by CA. The hydroxyl groups on PS reacted with CA by forming an ester linkage to introduce carboxyl groups. The results of elemental analysis of PS before and after modification by CA are summarized in Table 2. As indicated in Table 2, the carbon and hydrogen percentage of MPS reduced comparing with PS. Nevertheless, the oxygen percentage and molar ratio of O/C of MPS were higher than PS, which proved the success of modification by critic acid. 


\subsubsection{Thermogravimetric analysis of PS and MPS}

The TG curves of PS and MPS are presented in Fig. 3. According to the results of TG curves of PS and MPS in Fig. 3, it can be seen that the process of mass loss for PS and MPS was composed of three stage, including dehydration, active pyrolysis and passive pyrolysis. As shown in Fig. 3, the first stage of the mass loss of PS and MPS was ranged from 42 to $210^{\circ} \mathrm{C}$ and 42 to $188^{\circ} \mathrm{C}$ respectively, attributing to the loss of free water and bound water. At the second stage, the temperature range of PS was 210 to $340^{\circ} \mathrm{C}$, which can be associated with the active pyrolysis of cellulose and hemicelluloses. From Fig. 3, it can be clearly observed that the beginning of temperature of MPS was lower and the temperature range was wider than PS ascribed to the successful chemical modification by CA. Meanwhile, the third stage of the mass loss of PS ranged from 340 to $518^{\circ} \mathrm{C}$ which can be attributed to the further pyrolysis of cellulose $^{[27]}$. Comparing with PS, the temperature range of MPS at the third stage was wider than PS from 348 to $573^{\circ} \mathrm{C}$ due to the further decomposition of the carboxyl groups introduced and cellulose. Moreover, the lignin pyrolysis of PS and MPS existed the whole process ${ }^{[28]}$.

Fig. 3 TG curves of PS and MPS

\subsubsection{Surface morphology and BET surface area analysis}

As shown in Fig. 4, the SEM micrographs of PS before and after the chemical modification by CA were investigated. From Fig. 4a, it can be seen that the microtopography of PS was irregular and porous. In comparing to the micrograph of 
PS, the surface structures of BPS and MPS did not change obviously and the porous structure still existed. This indicated that modification did not change the porous structure of PS, which still can play an important role in adsorption of contaminants.

Fig. 4 SEM micrographs of PS (a), BPS (b) and MPS (c)

The BET surface area and pore volume of PS and MPS were listed in Table 3. In comparison with PS, the BET surface area of MPS significantly decreased from 0.330 to $0.0296 \mathrm{~m}^{2} / \mathrm{g}$, which could be ascribed to the change of the pore distribution after the modification by critic acid. It's clear that the pore volume was low about $3.675 \mathrm{dm}^{3} / \mathrm{g}$ for PS, however the pore volume of MPS was lower about $2.710 \mathrm{dm}^{3} / \mathrm{g}$. It could be explicated that some large pores were clogged by CA during the chemical modification. Therefore, the results indicated that the adsorption capacity of heavy metals and dyes can be improved due to the introduction of carboxyl groups and the presence of porous structure.

Table 3 The BET surface area and pore volume of PS and MPS

\subsubsection{Fourier transform infrared spectroscopy analysis}

The FTIR spectra of PS before and after modification and all MPS samples after the adsorption of heavy metals and MB are shown in Fig. 5. Based on the contents of PS mainly containing cellulose, hemicellulose and lignin, it's obvious that a large of groups (carboxyl, hydroxyl, ether and so on) could be observed from FTIR spectra.

As indicated in Fig. 5, the spectrum of PS showed a strong and broad peak around $3441 \mathrm{~cm}^{-1}$ attributed to the existence of $\mathrm{OH}$ groups. The peak appeared at $2907 \mathrm{~cm}^{-1}$ was 
ascribed to the $\mathrm{CH}$ stretching band. The characteristic stretching vibration adsorption band observed at $1745 \mathrm{~cm}^{-1}$ was assigned to the carboxyl groups in hemicellulose. The band around $1515 \mathrm{~cm}^{-1}$ was the amide group. The adsorption peak for $1254 \mathrm{~cm}^{-1}$ was due to the syringyl ring and CO stretching in lignin and xylan (hemicellulose) and the band around $1039 \mathrm{~cm}^{-1}$ was the characteristic of the COC and $\mathrm{OH}$ groups of primary hydroxyl stretching in cellulose and hemicellulose ${ }^{[9,20]}$. In comparison with FTIR spectrum of PS, it can be seen that the intensity of the peak of carboxyl group obviously increased after the chemical modification of PS by CA. The strong stretching band of carboxyl group located at $1738 \mathrm{~cm}^{-1}$ was attributed to the esterification reaction by citric acid $^{[29]}$. In addition, after the modification of PS by CA, the stretching vibration bands of $\mathrm{OH}$ shifted from $3441 \mathrm{~cm}^{-1}$ to $3431 \mathrm{~cm}^{-1}$ and obviously broadened, but the peak at $2907 \mathrm{~cm}^{-1}$ changed little, the peak of amide group at $1515 \mathrm{~cm}^{-1}$ became sharp, the peak around $1254 \mathrm{~cm}^{-1}$ disappeared, and hydroxyl groups shifted from $1039 \mathrm{~cm}^{-1}$ to 1031 $\mathrm{cm}^{-1}$.

After the completion of adsorption of heavy metals and MB by MPS, it can be seen that the FTIR spectra obviously changed comparing with MPS. From Fig. 5, the $\mathrm{OH}$ stretching bands around $3441 \mathrm{~cm}^{-1}$ of all samples loaded by heavy metals and MB shifted little and broadened, which were ascribed to the formation of hydrogen bonds between the hydroxyl groups on MPS and heavy metals or MB. The intensity of the peaks at $1738 \mathrm{~cm}^{-1}$ and $1515 \mathrm{~cm}^{-1}$ decreased especially for MPS loaded by heavy metals. It can be assigned to the chelation between carboxyl or amide groups on MPS and heavy metals or MB. However, the peak decrease of MPS loaded by MB was slight comparing 
with heavy metals onto MPS. The results can be elaborated by the different adsorption mechanism between heavy metals and MB. Meanwhile, it's obvious that the peak at $1031 \mathrm{~cm}^{-1}$ of MPS decreased after adsorption indicating that the COC and $\mathrm{OH}$ groups participated in the adsorption reaction of heavy metals and MB. The intensity of the band of MPS loaded by MB located at $1031 \mathrm{~cm}^{-1}$ decreased. Moreover, the peaks of MPS loaded by heavy metals shifted slightly and the corresponding peak intensity also weakened comparing with MPS. The peak for MPS-Cd ${ }^{2+}$ loaded was $1023 \mathrm{~cm}^{-1}, 1039$ $\mathrm{cm}^{-1}$ for MPS-Cu${ }^{2+}$ and $1016 \mathrm{~cm}^{-1}$ for MPS-Pb ${ }^{2+}$.

Fig. 5 FTIR spectra of PS, MPS and MPS after adsorption of heavy metals and MB ( MB-MPS: MPS after adsorption of MB, Cd-MPS: MPS after adsorption of Cd, Cu-MPS: MPS after adsorption of $\mathrm{Cu}, \mathrm{Pb}-\mathrm{MPS}$ : MPS after adsorption of $\mathrm{Pb}$ )

\subsection{Effect of pH on heavy metals and MB adsorption}

The solution $\mathrm{pH}$ has a significant effect on adsorption capacity in the adsorption process. Fig. 6 shows the change trends of $\mathrm{Cd}, \mathrm{Cu}, \mathrm{Pb}$ and $\mathrm{MB}$ with the increase of $\mathrm{pH}$. As shown in Fig. 6, the uptake amounts of $\mathrm{Cd}, \mathrm{Cu}, \mathrm{Pb}$ and $\mathrm{MB}$ was low at low $\mathrm{pH}$, which attributed to strong competition adsorption between adsorbates and hydrogen ions and electrostatic repulsion from the surface of adsorbent. However, it can be seen that all adsorption capacities increased with the increasing $\mathrm{pH}$ due to the reducing concentration of $\mathrm{H}^{+}$, the increasing electrostatic attractions and ion-exchange.

It's well known that the heavy metal species present in aqueous solution and the surface charge of adsorbent can be significantly affected by $\mathrm{pH}^{[9]}$. At low $\mathrm{pH}$, there existed strong electrostatic repulsion due to the positive charge of adsorbent and strong 
competition between $\mathrm{H}^{+}$and heavy metals. With the increase of $\mathrm{pH}$, the positive charge on the adsorbent surface started to decrease and charged negatively resulting in the adsorption capacity increasing. However, when the solution $\mathrm{pH}$ containing heavy metal ions reached a certain value, it's easy to form precipitation. According to the literature reported, when the $\mathrm{pH}$ value is over 5.8, the precipitation of $\mathrm{Cu}(\mathrm{OH})_{2}$ and $\mathrm{Pb}(\mathrm{OH})_{2}$ start to form ${ }^{[30]}$. As for $\mathrm{Cd}$, the $\mathrm{Cd}(\mathrm{OH})_{2}$ precipitation exist at $\mathrm{pH} 7^{[19]}$. Therefore, to avoid the precipitation playing a major role, the next adsorption experiments of $\mathrm{Cu}$ and $\mathrm{Pb}$ were investigated at $\mathrm{pH} 5$, and $\mathrm{Cd}$ was at $\mathrm{pH}$ 6. With regard to $\mathrm{MB}, \mathrm{MB}$ in solution was positively charged. At $\mathrm{pH}<4$, the uptake capacity was low due to the strong competition between $\mathrm{H}^{+}$and active sites on $\mathrm{MB}$. At $\mathrm{pH}>4$, it can been seen that the adsorption amounts increased and remained stable after $\mathrm{pH}$ 6, attributed to electrostatic attraction. So pH 6 was selected to study the adsorption of MB at next experiments.

Fig. 6 Effect of solution $\mathrm{pH}$ on heavy metals and MB adsorption onto MPS (initial concentration : $200 \mathrm{mg} / \mathrm{L}$; dosage: $0.2 \mathrm{~g} ; 30^{\circ} \mathrm{C}$; contact time: $2 \mathrm{~h}$ )

\subsection{Effects of adsorbent dosage}

The effects of different adsorbent dosage from 1 to $10 \mathrm{~g} / \mathrm{L}$ on the removal rates of $\mathrm{Cu}, \mathrm{Cd}, \mathrm{Pb}$ and MB by MPS are shown in Fig. 7. It can be seen from Fig. 7a the all adsorption rates increased with the increase of adsorption dosage. It can be ascribed to more active sites and greater surface area provided with the increasing amount of adsorbent. Fig. 7b shows that the adsorption capacities of heavy metals and MB decreased with the increase of adsorbent dosage, which can be due to un-saturation of 
adsorption sites that were conductive to the decrease of adsorption uptake ${ }^{\text {[31] }}$

Fig. 7 Effect of adsorbent dosages on heavy metals and MB onto MPS (initial concentration : 200 mg/L; pH: Cu, Pb-5, Cd, MB-6; 30 ; contact time: 2 h)

\subsection{Adsorption kinetics}

Fig. 8 illustrates the effects of contact time on adsorption capacity of heavy metals and MB. As shown in Fig. 8a, the adsorption process was consisted of two stages: a rapid adsorption stage over a few time due to explosion of more adsorption sites and a slower adsorption stage until the equilibrium state reached attributed to the saturation of active sites. From Fig. 8a, it's clear that heavy metals and MB were rapid to reach the adsorption equilibrium. Therefore, 180 min was suitable to be chosen as contact time for the further experiments.

In order to better understand the adsorption kinetics of heavy metals and MB by MPS, the experiment data were fitted with pseudo-second-order and intra-particle diffusion models. The pseudo-second-order kinetic model ${ }^{[32]}$ is expressed as:

$$
\frac{t}{q_{t}}=\frac{1}{k q_{e}^{2}}+\frac{t}{q_{e}}
$$

The intra-particle diffusion model ${ }^{[33]}$ is given as follows:

$$
q_{t}=k_{p} t^{0.5}+C
$$

Where $q_{e}(\mathrm{mg} / \mathrm{g})$ and $q_{t}(\mathrm{mg} / \mathrm{g})$ are the adsorption uptake of heavy metals and MB by MPS at equilibrium and at time t, respectively. $k\left(\mathrm{~g} \cdot \mathrm{mg}^{-1} \cdot \mathrm{min}^{-1}\right)$ is the pseudo- 
second-order rate constant calculated from the plots of $t / q_{t}$ against t, and $k_{p}\left(\mathrm{mg} . \mathrm{h}^{0.5}\right.$. $\mathrm{g}^{-1}$ ) is the intra-particle diffusion rate constant gained from the slope of straight-line portions of the plots of $q_{t}$ against $t^{0.5}$, and $\mathrm{C}$ is a constant obtained from the intercept of gained from the plots.

As shown in Fig. 8b, it's obvious that the experiment data can be fitted with pseudo-second-order kinetic models well. The regression coefficients $\left(\mathrm{R}^{2}\right)$ data listed in Table 4 were high, about 0.9996, 0.9983, 0.9843 and 0.9991 for $\mathrm{MB}, \mathrm{Cd}, \mathrm{Cu}$ and $\mathrm{Pb}$ respectively. Meanwhile, the calculated $q_{e}$ values of heavy metals and MB were in agreement with the experimental data. Therefore, it indicated that the chemical adsorption could be the rate limiting step in the heavy metals and MB adsorption $\operatorname{process}^{[4]}$.

In Fig. 8c, it can be clearly seen that the intra-particle diffusion models were consisted of two straight lines, which confirmed that the intra-particle diffusion contained two steps: the liner step with a rapid adsorption process assigned to the external surface adsorption or boundary layer diffusion, and the intra-particle diffusion step ${ }^{[5]}$. Nevertheless, the liner plots in Fig. 8c did not pass through the origin indicating that the intra-particle diffusion were not the rate controlling step.

Table 4 Kinetic parameters for MB, Cd, Cu, Pb adsorption on M-PS

Fig. 8 Effect of contact time on heavy metals and MB (a), the pseudo-second-order kinetic model (b) and intra-particle diffusion plots (c) on heavy metals and MB adsorption by MPS (initial concentration: 200 mg/L; dosage: 0.2 g; $\mathrm{pH}$ : Cu, Pb-5, Cd, MB-6; 30 C) 


\subsection{Adsorption isotherms}

Batch experiments were carried out for investigating the effects of initial concentrations on adsorption of heavy metals and MB by MPS. As depicted in Fig. 9a, the amounts of heavy metals and MB adsorption quickly increased with the increase of adsorbent dosage and then slowly increased until the equilibrium gradually reached. At low concentrations, the increasing uptakes of heavy metals and MB were ascribed to the sufficient active sites on the adsorbent. Furthermore, the increasing initial concentrations of heavy metals and MB were conducive to form strong driving force to overcome mass transfer resistance in adsorption process. However, at the high concentration, more heavy metals and MB were left un-adsorbed due to the the saturation of binding sites of MPS so that the capacities increased slowly and almost kept stable.

To evaluate the adsorption capacities of heavy metals and MB by M-PS and illustrate the characterization of adsorption process, Langmuir and Freundlich models were employed in this study. Langmuir isotherm assumes a monolayer adsorption over a homogeneous adsorbent surface and each molecule adsorbed onto the surface ${ }^{[16]}$. Langmuir isotherm model ${ }^{[34]}$ can be expressed as follows:

$$
\frac{C_{e}}{q_{e}}=\frac{C_{e}}{q_{\max }}+\frac{1}{q_{\max } K_{L}}
$$

Where $q_{e}$ and $C_{e}$ are the equilibrium adsorption capacity $(\mathrm{mg} / \mathrm{g})$ and equilibrium concentration $(\mathrm{mg} / \mathrm{L})$, respectively. $q_{\max }$ is the maximum adsorption capacity (mg/g), and $K_{L}$ is the Langmuir constant (L/mg). 
Freundlich model ${ }^{[35,36]}$ which is still an empirical equation used to simulate the multilayer adsorption is represented as follows:

$$
\log q_{e}=\log k_{f}+\frac{1}{n} \log C_{e}
$$

Where $q_{e}$ and $C_{e}$ are the equilibrium concentration $(\mathrm{mg} / \mathrm{L})$ and equilibrium adsorption capacity (mg/g), respectively. $k_{f}$ and $\mathrm{n}$ are the Freundlich constant. The Langmuir and Freundlich constants of the adsorption of heavy metals and MB were calculated from the slopes and intercepts of the plots of $C_{e} / q_{e}$ versus $C_{e}$ (Fig. 9b) and $\log q_{e}$ versus $C_{e} \quad$ (Fig. 9c) and summarized in Table 5.

As illuminated in Fig. 9 and Table 5, the results indicated that the adsorption process of $\mathrm{Cd}, \mathrm{Cu}$ and $\mathrm{Pb}$ can be fitted with Langmuir isotherm model well with high regression coefficients ( $\left.R^{2}>0.9\right)$. In addition, the experimental data of $\mathrm{Pb}$ and $\mathrm{Cu}$ can be fitted with Freundlich model indicating that the adsorption process of $\mathrm{Pb}$ and $\mathrm{Cu}$ might be governed by multiple mechanisms. Regarding to $\mathrm{MB}$, the adsorption process was more suitable for being described by Freundlich isotherm model ( $R^{2}=0.9244$ ) than Langmuir isotherm model $\left(R^{2}=0.8705\right)$, indicating that the adsorption process of MB can be multilayer adsorption. For the adsorption of heavy metals, the maximum uptakes evaluated by Langmuir isotherm followed the order: $\mathrm{Pb}>>\mathrm{Cd}>\mathrm{Cu}$, and were 118.76, 37.48 and $32.22 \mathrm{mg} / \mathrm{g}$, respectively. In the case of MB, the maximum adsorption capacity was $178.25 \mathrm{mg} / \mathrm{g}$. These results also further proved that MPS was a promising adsorbent to treatment effluent containing heavy metals and dyes. 
Fig. 9 Effect of initial concentration on heavy metals and MB (a), Langmuir isotherm model (b) and Freudlich isotherm model (c) on heavy metals and MB adsorption by MPS (dosage: 0.2 g; pH: Cu, Pb-5, Cd, MB-6; $30^{\circ} \mathrm{C}$; contact time: 2 h)

\subsection{Column studies}

To study the practical application of MPS, the column experiments were conducted to investigate the adsorption of $\mathrm{Pb}^{2+}$ and $\mathrm{MB}$. The breakthrough curves of MPS were presented in Fig. 10. As shown in Fig. 10, it can be seen that the breakthrough times of $\mathrm{Pb}^{2+}$ and $\mathrm{MB}$ increased with the increase of bed height. Since more time was spent to pass through the column with the higher bed height, $\mathrm{Pb}^{2+}$ and $\mathrm{MB}$ had longer contact time with MPS leading to higher capacity.

Fig. 10 Breakthrough curves of $\mathrm{Pb}^{2+}$ and MB with different bed heights (bed height: $5 \mathrm{~cm}, 6 \mathrm{~cm}, 7$ cm; initial concentration: $200 \mathrm{mg} / \mathrm{L}$; room temperature; $\mathrm{pH}$ : Pb-5, MB-6; flow rate: $3.8 \mathrm{ml} / \mathrm{min}$ )

\section{Conclusions}

In this paper, peach stones modified by citric acid as a new adsorbent were studied to remove heavy metals and $\mathrm{MB}$ from wastewater. Batch adsorption experiments showed that $\mathrm{pH}$, adsorbent dosage, contact time and initial concentration have significant effects on the adsorption of heavy metals and MB. Kinetics studies indicated that the experimental data of heavy metals and MB can be fitted with pseudo-second order model well. Therefore, the chemical adsorption was the rate-limiting step for the adsorption of heavy metals and MB. Isotherm studies suggested that heavy metals can be fitted with the Langmuir isotherm well and $\mathrm{Pb}$ can be fitted with Freundlich, but MB 
followed Freundlich isotherm model well. Furthermore, column experiments of $\mathrm{Pb}^{2+}$ and $\mathrm{MB}$ also were conducted. The results indicated that $\mathrm{Pb}^{2+}$ and $\mathrm{MB}$ have high adsorption capacity. All results confirm that MPS has a potential for the removal of heavy metals and MB. And it also realized the regeneration use of PS well and avoided the waste of resources.

\section{Acknowledgements}

This work was supported by China Postdoctoral Science Foundation (Grant No. 2015M572477) and the Opening Project (YQKF201406) of Oil \& Gas Applied Chemistry Key Laboratory of Sichuan Province.

\section{References}

1. Adamczuk, A.;\& Kołodyńska, D. (2015). Equilibrium, thermodynamic and kinetic studies on removal of chromium, copper, zinc and arsenic from aqueous solutions onto fly ash coated by chitosan. Chemical Engineering Journal, 274, 200.

2. Zhang, W.; Li, H.; Kan, X.; Lei, D.; Han, Y.; Jiang, Z.;Yang, Hu.; Li, A.; Cheng, R. (2012). Adsorption of anionic dyes from aqueous solutions using chemically modified straw. Bioresource Technology, 117(10), 40.

3. Zhou, Y.; Zhang, R.; Gu, X.; Lu, J.(2015) Adsorption of divalent heavy metal ions from aqueous solution by citric acid modified pine sawdust. Separation Science and Technology, 50(2), 245.

4. Liu, F.; Zou, H.; Hu, J.; Liu, H.; Peng, J.; Chen, Y.; Lu, F; Huo Y. (2016) Fast removal of methylene blue from aqueous solution using porous soy protein isolate based composite 
beads. Chemical Engineering Journal, 287, 410.

5. Mahmoud, D. K.; Salleh, M. A. M.; Wan, A. W. A. K.; Idris, A.; Abidin, Z. Z. (2012) Batch adsorption of basic dye using acid treated kenaf fibre char: equilibrium, kinetic and thermodynamic studies. Chemical Engineering Journal, s 181-182(2), 449.

6. Zeng, G.; He, Y.; Zhan, Y.; Zhang, L.; Pan, Y.; Zhang, C.; Yu, Z. (2016) Novel polyvinylidene fluoride nanofiltration membrane blended with functionalized halloysite nanotubes for dye and heavy metal ions removal. Journal of Hazardous Materials, 317, 60.

7. Sajab, M. S.; Chia, C. H.; Zakaria, S.; Jani, S. M.; Ayob, M. K.; Chee, K. L. (2011) Citric acid modified kenaf core fibres for removal of methylene blue from aqueous solution. Bioresource Technology, 102(15), 7237

8. Mata, Y. N.; Blázquez, M. L.; Ballester, A.; González, F.; Muñoz, J. A. (2009) Biosorption of cadmium, lead and copper with calcium alginate xerogels and immobilized fucus vesiculosus. Journal of Hazardous Materials, 163(s 2-3), 555.

9. Al-Ghouti, M. A.; Li, J.; Salamh, Y.; Al-Laqtah, N.; Walker, G.; Ahmad, M. N. (2010) Adsorption mechanisms of removing heavy metals and dyes from aqueous solution using date pits solid adsorbent. Journal of Hazardous Materials, 176(1-3), 510.

10. Kaya, K.; Pehlivan, E.; Schmidt, C.; Bahadir, M. (2014) Use of modified wheat bran for the removal of chromium(VI) from aqueous solutions. Food Chemistry, 158(8), 112.

11. Krishnani, K. K.; Meng, X.; Christodoulatos, C.; Boddu, V. M. (2008) Biosorption mechanism of nine different heavy metals onto biomatrix from rice husk. Journal of Hazardous 
Materials, 153(3), 1222.

12. Li, Y.; Zhao, B.; Zhang, L.; Han, R. (2013) Biosorption of copper ion by natural and modified wheat straw in fixed-bed column, Desalination and Water Treatment, 51, 5735.

13. Witek-Krowiak, A.; Harikishore, K. R. D. (2013) Removal of microelemental Cr(III) and Cu(II) by using soybean meal waste--unusual isotherms and insights of binding mechanism. Bioresource Technology, 127(127C), 350.

14. Wang, X. S.; Qin, Y. (2006) Removal of Ni(II), Zn(II) and Cr(VI) from aqueous solution by alternanthera philoxeroides biomass. Journal of Hazardous Materials, 138(3), 582.

15. Velazquezjimenez, L. H.; Pavlick, A.; Rangelmendez, J. R. (2013) Chemical characterization of raw and treated agave bagasse and its potential as adsorbent of metal cations from water. Industrial Crops \& Products, 43(1), 200.

16. Sajab, M. S.; Chia, C. H.; Zakaria, S.; Khiew, P. S. (2013) Cationic and anionic modifications of oil palm empty fruit bunch fibers for the removal of dyes from aqueous solutions. Bioresource Technology,128C(1), 571.

17. Low, K. S.; Lee, C. K.; Mak, S. M. (2004) Sorption of copper and lead by citric acid modified wood. Wood Science and Technology, 38(8), 629.

18. Pehlivan, E.; Altun, T.; Parlayici, S. (2013) Modified barley straw as a potential biosorbent for removal of copper ions from aqueous solution. Food Chemistry, 135(4), 2229.

19. Leyva-Ramos, R., Landin-Rodriguez L. E., Leyva-Ramos S. \& Medellin-Castillo N. A. 2012 Modification of corncob with citric acid to enhance its capacity for adsorbing cadmium(ii) from 
water solution. Chemical Engineering Journal, 180(3), 113.

20. Zhang, R.; Zhou, Y.; Gu, X.; Lu, J. (2015) Competitive adsorption of Methylene Blue and Cu2+ onto citric acid modified pine sawdust. CLEAN-Soil, Air, Water, 43(1), 96.

21. Rashed, M. N. (2006) Fruit stones from industrial waste for the removal of lead ions from polluted water. Environmental Monitoring \& Assessment, 119(1-3), 31.

22. Hansen H. K., Arancibia F. \& Gutiérrez C. 2010 Adsorption of copper onto agriculture waste materials. Journal of Hazardous Materials,180(1-3), 442.

23. Ntuli, V.; Hapazari, I. (2012) Sustainable waste management by production of activated carbon from agroforestry residues. South African Journal of Science, 109(1-2), 1.

24. Girgis, B.S.; Elkady, A. A.; Attia, A.A.; Fathy, N.A. M. A A.W. (2009) Impact of Air Convection on H3PO4-Activated Biomass, Carbon Letters, 10 (2), 114.

25. Marshall, W. E., Wartell, L. H., Boler D. E., Johns M. M. \& Toles C. A. 1999 Enhanced metal adsorption by soybean hulls modified with citric acid. Bioresource Technology, 69(69), 263-268.

26. Wing, R. E. 1996 Corn fiber citrate: preparation and ion-exchange properties. Industrial Crops \& Products, 5(4), 301-305.

27. Rayón, E.; Ferrandiz, S.; Rico, M. I.; López, J.; Arrieta, M. P. (2014) Microstructure, mechanical, and thermogravimetric characterization of cellulosic by-products obtained from biomass seeds. International Journal of Food Properties, 18(6), 1211.

28. Yang, H.; Yan, R.; Chen, H.; Dong, H. L.; Zheng, C. (2007) Characteristics of hemicellulose, cellulose and lignin pyrolysis. Fuel,86(12-13), 1781. 
29. Zhu, B.; Fan, T.; Zhang, D. (2008) Adsorption of copper ions from aqueous solution by citric acid modified soybean straw. Journal of Hazardous Materials, 153(1-2), 300.

30. Wang, H.; Gao, B.; Wang, S.; Fang, J.; Xue, Y.; Yang, K. (2015) Removal of Pb(II), Cu(II), and $\mathrm{Cd}(\mathrm{II})$ from aqueous solutions by biochar derived from $\mathrm{KMnO} 4$ treated hickory wood. Bioresource Technology, 197, 356.

31. Gong, J. L.; Wang, X. Y.; Zeng, G. M.; Chen, L.; Deng, J. H.; Zhang, X. R.; Niu, Q. (2012) Copper (II) removal by pectin-iron oxide magnetic nanocomposite adsorbent. Chemical Engineering Journal, 185-186(1), 100.

32. Pitsari, S.; Tsoufakis, E.; Loizidou, M. (2013) Enhanced lead adsorption by unbleached newspaper pulp modified with citric acid. Chemical Engineering Journal, 223(3), 18.

33. Fan, H. L.; Li, L.; Zhou, S. F.; Liu, Y. Z. (2016) Continuous preparation of Fe3O4 nanoparticles combined with surface modification by L-cysteine and their application in heavy metal adsorption. Ceramics International, 42(3), 4228.

34. Badruddoza A. Z; Tay, A. S.; Tan, P. Y.; Hidajat, K.; Uddin, M. S. (2010) Carboxymethyl- $\beta-$ cyclodextrin conjugated magnetic nanoparticles as nano-adsorbents for removal of copper ions: synthesis and adsorption studies. Journal of Hazardous Materials, 185(2-3), 1177.

35. Chakravarty, S.; Pimple, S.; Chaturvedi, H. T.; Singh, S.; Gupta, K. K. (2008) Removal of copper from aqueous solution using newspaper pulp as an adsorbent. Journal of Hazardous Materials, 159(2-3), 396.

36. Qiu, H.; Yan, J.; Lan, G.; Liu, Y.; Song, X.; Peng, W.; Cui, Y. (2016). Removal of Cu2+ from 
wastewater by modified xanthan gum (xg) with ethylenediamine (eda). Rsc Advances, 6 . 


\section{Figure captions:}

\section{Fig. 1 Standard curve of MB}

Fig. 2 Esterification reaction of peach stone cellulose and critic acid

Fig. 3 TG curves of PS and MPS

Fig. 4 SEM micrographs of PS (a), BPS (b) and MPS (c)

Fig. 5 FTIR spectra of PS, MPS and MPS after adsorption of heavy metals and MB ( MB-MPS: MPS after adsorption of MB, Cd-MPS: MPS after adsorption of Cd, Cu-MPS: MPS after adsorption of $\mathrm{Cu}, \mathrm{Pb}-\mathrm{MPS}$ : MPS after adsorption of $\mathrm{Pb}$ )

Fig. 6 Effect of solution pH on heavy metals and MB adsorption onto MPS (initial concentration : $200 \mathrm{mg} / \mathrm{L}$; dosage: $0.2 \mathrm{~g}$; 30]; contact time: $180 \mathrm{~min}$ )

Fig. 7 Effect of adsorbent dosages on heavy metals and MB onto MPS (initial concentration : 200 $\mathrm{mg} / \mathrm{L} ; \mathrm{pH}: \mathrm{Cu}, \mathrm{Pb}-5, \mathrm{Cd}, \mathrm{MB}-6$; 30요; contact time: $180 \mathrm{~min}$ )

Fig. 8 Effect of contact time on heavy metals and MB (a), the pseudo-second-order kinetic model (b) and intra-particle diffusion plots (c) on heavy metals and MB adsorption by MPS. Fig. 9 Effect of initial concentration on heavy metals and $M B(a)$, Langmuir isotherm model (b) and Freudlich isotherm model (c) on heavy metals and MB adsorption by MPS.

Fig. 10 Breakthrough curves of $\mathrm{Pb}^{2+}$ and $\mathrm{MB}$ with different bed heights (bed height: $5 \mathrm{~cm}, 6 \mathrm{~cm}, 7$ $\mathrm{cm}$; initial concentration: $200 \mathrm{mg} / \mathrm{L}$; room temperature; $\mathrm{pH}$ : $\mathrm{Pb}-5, \mathrm{MB}-6$; flow rate: $3.8 \mathrm{ml} / \mathrm{min}$ ) 


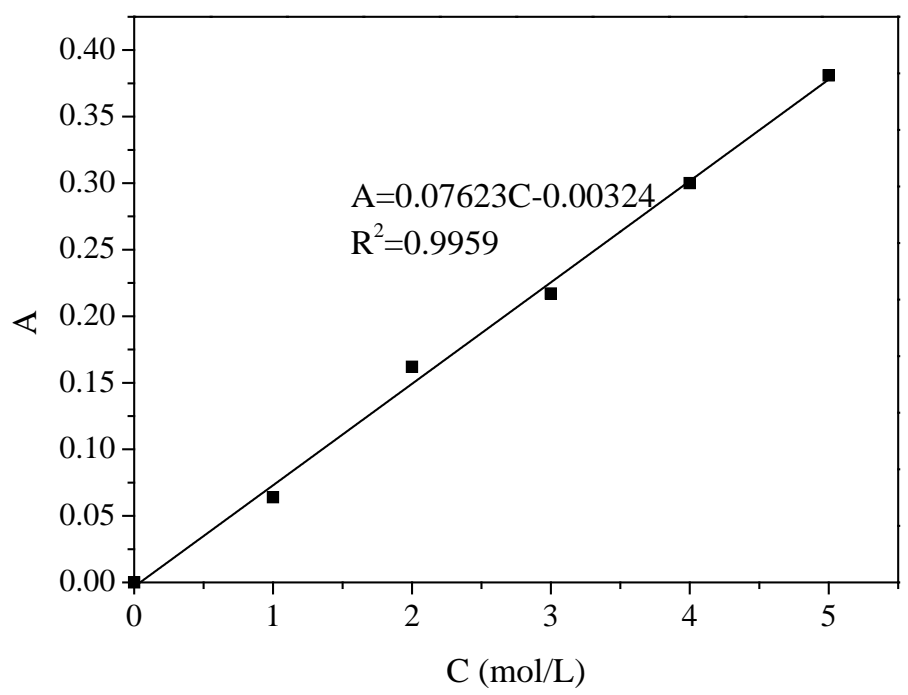

Fig. 1 Standard curve of MB

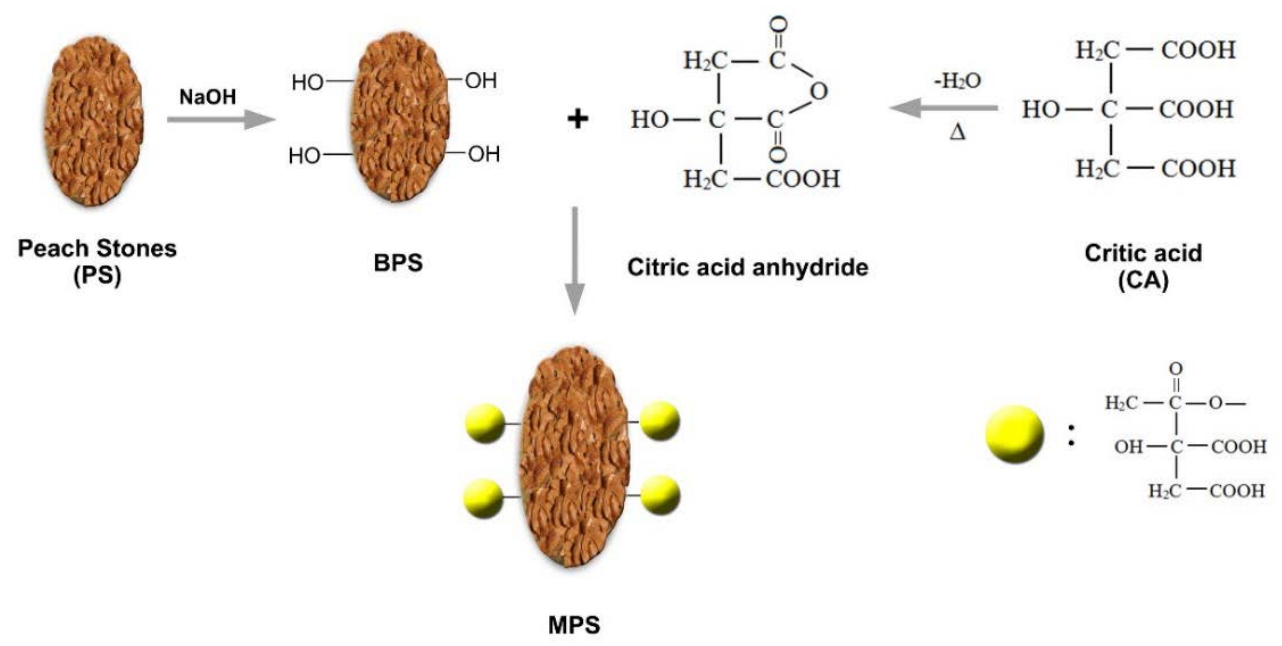

Fig. 2 Esterification reaction of peach stone cellulose and critic acid 


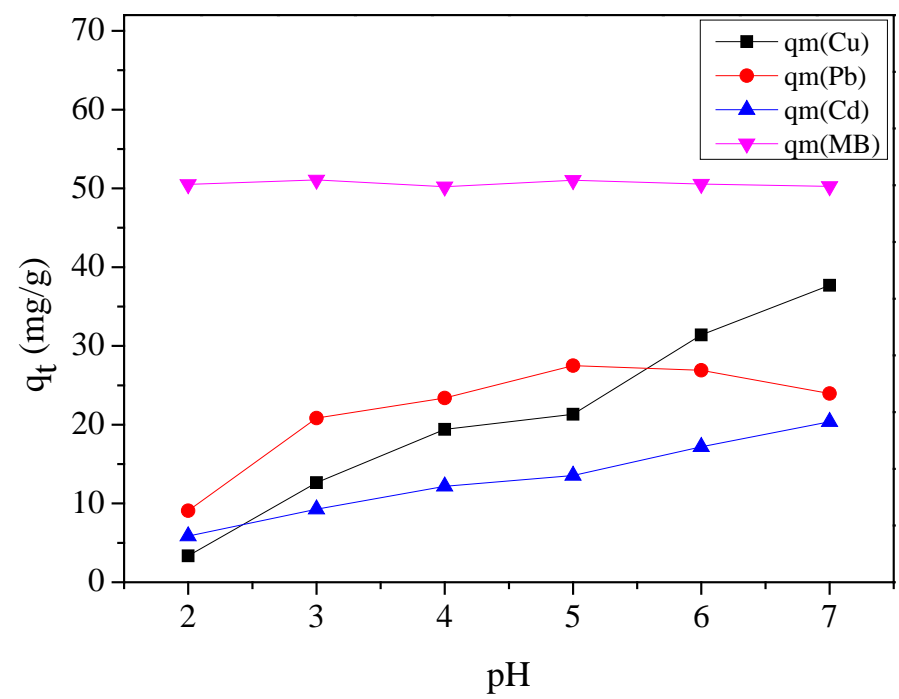

Fig. 3 TG curves of PS and MPS
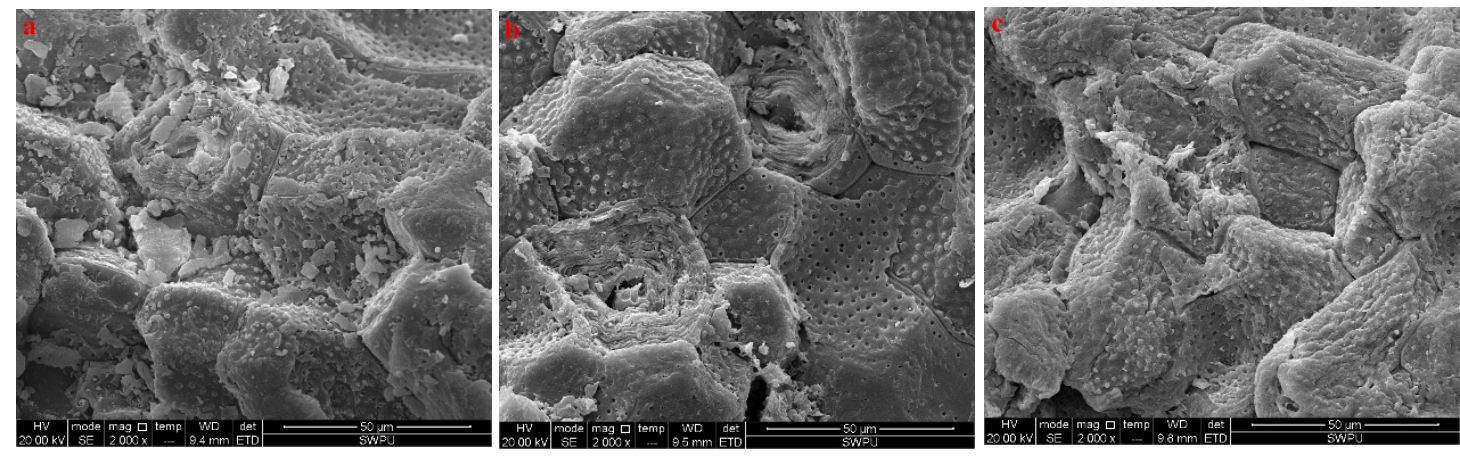

Fig. 4 SEM micrographs of PS (a), BPS (b) and MPS (c) 


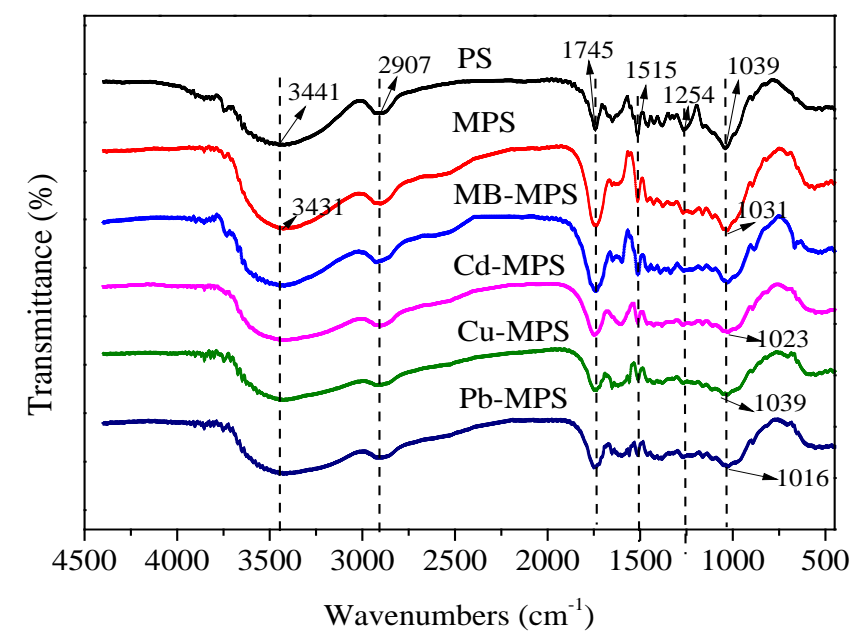

Fig. 5 FTIR spectra of PS, MPS and MPS after adsorption of heavy metals and MB.

( MB-MPS: MPS after adsorption of MB, Cd-MPS: MPS after adsorption of Cd, Cu-MPS: MPS after adsorption of $\mathrm{Cu}, \mathrm{Pb}-\mathrm{MPS}$ : MPS after adsorption of $\mathrm{Pb}$ )

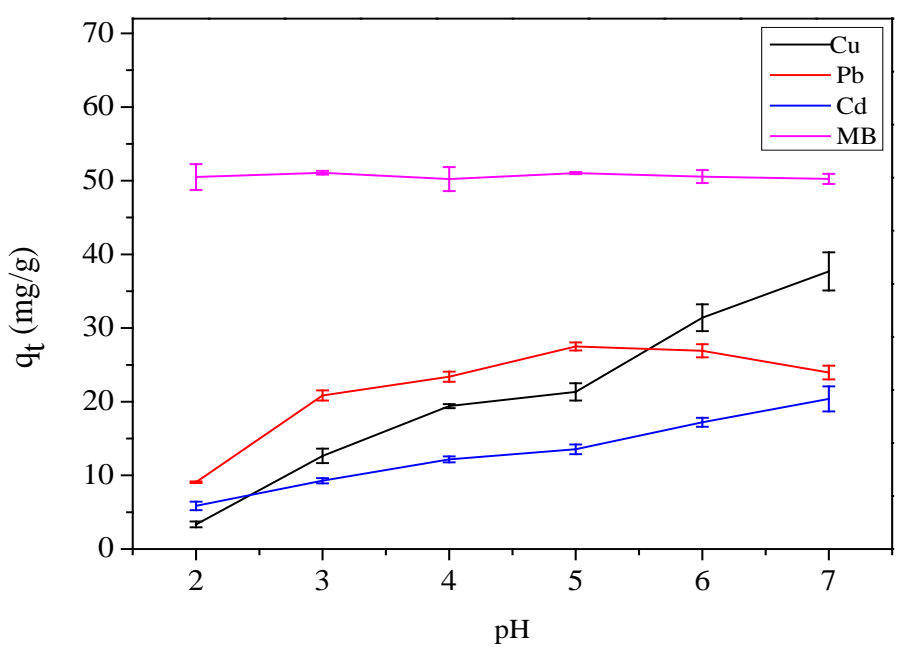

Fig. 6 Effect of solution $\mathrm{pH}$ on heavy metals and MB adsorption onto MPS (initial concentration : $200 \mathrm{mg} / \mathrm{L}$; dosage: $0.2 \mathrm{~g} ; 30^{\circ} \mathrm{C}$; contact time: $180 \mathrm{~min}$ ) 

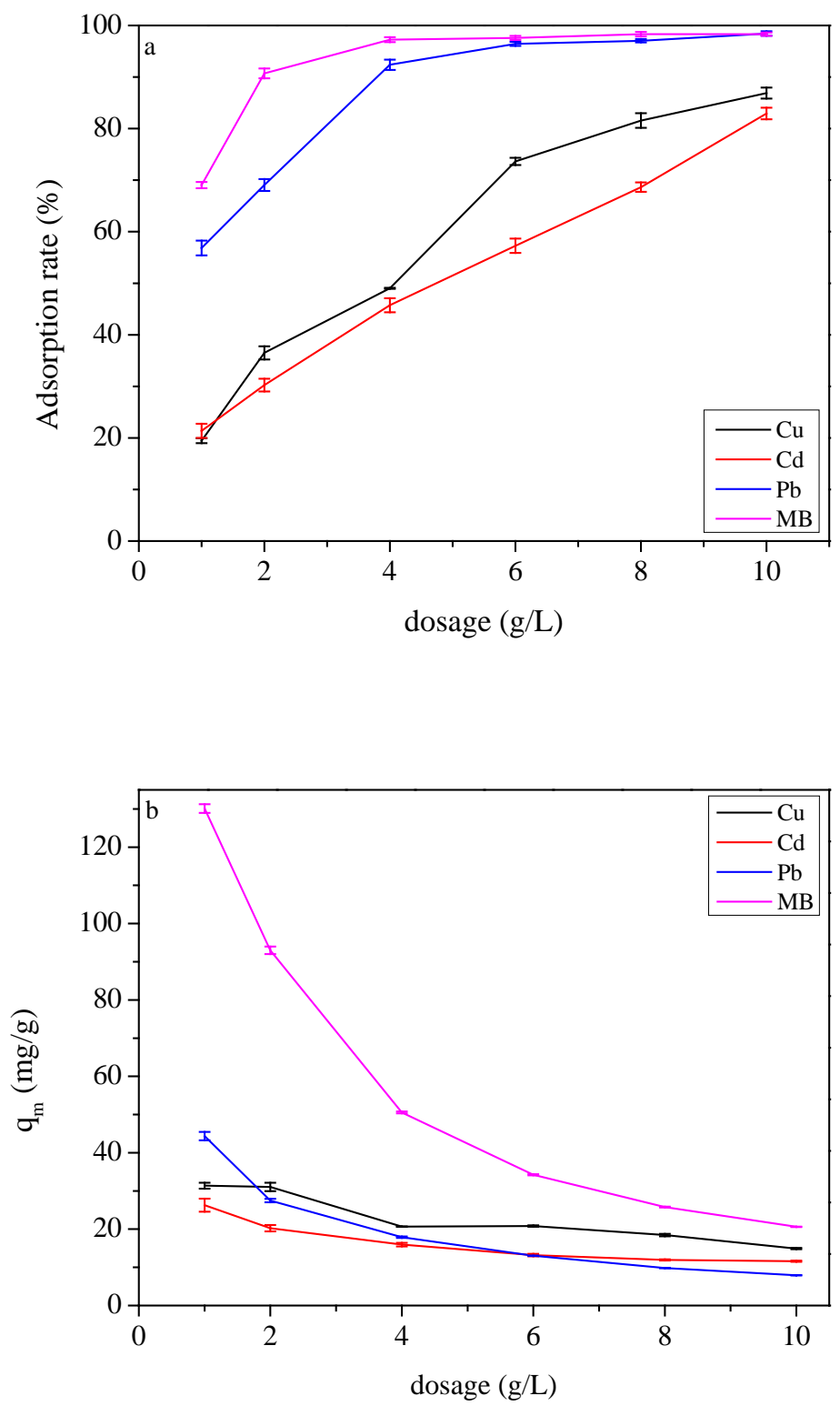

Fig. 7 Effect of adsorbent dosages on heavy metals and MB onto MPS (initial concentration : 200 $\mathrm{mg} / \mathrm{L} ; \mathrm{pH}: \mathrm{Cu}, \mathrm{Pb}-5, \mathrm{Cd}, \mathrm{MB}-6 ; 30^{\circ} \mathrm{C}$; contact time: $180 \mathrm{~min}$ ) 

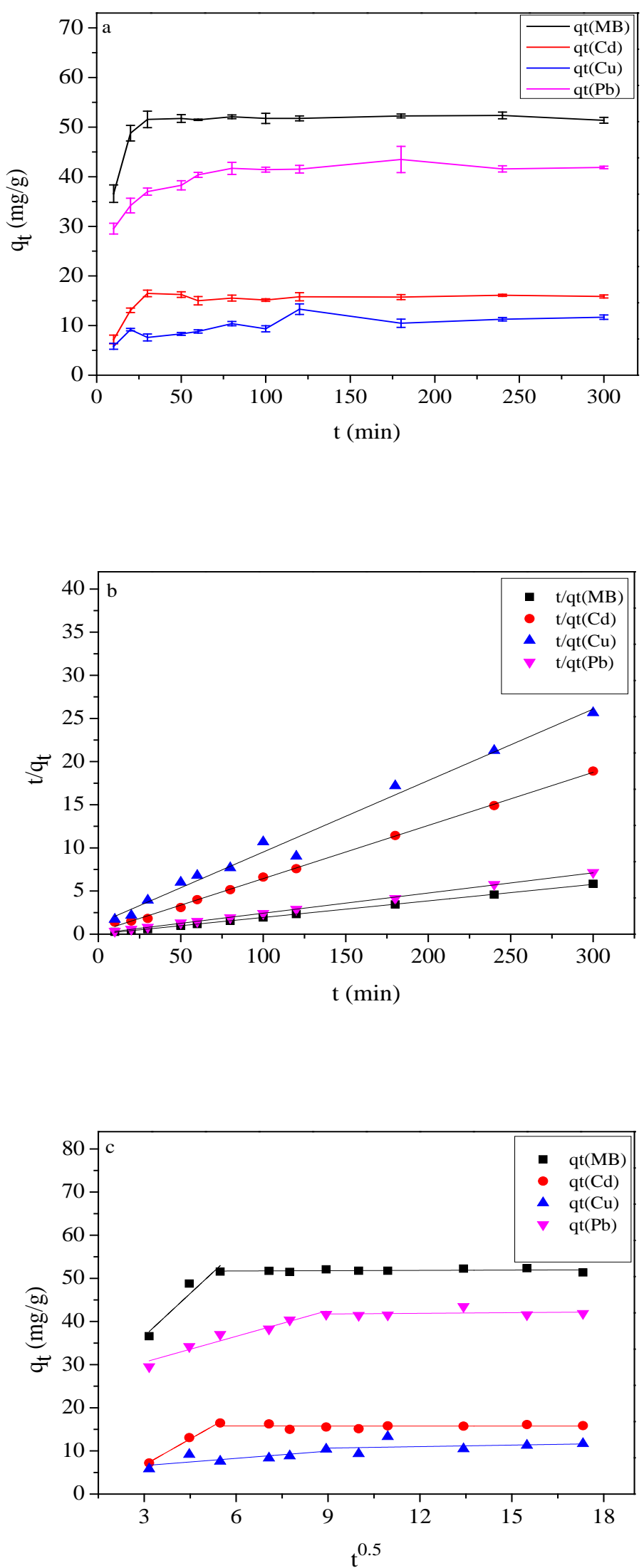

Fig. 8 Effect of contact time on heavy metals and MB (a), the pseudo-second-order kinetic 
model (b) and intra-particle diffusion plots (c) on heavy metals and MB adsorption by MPS.
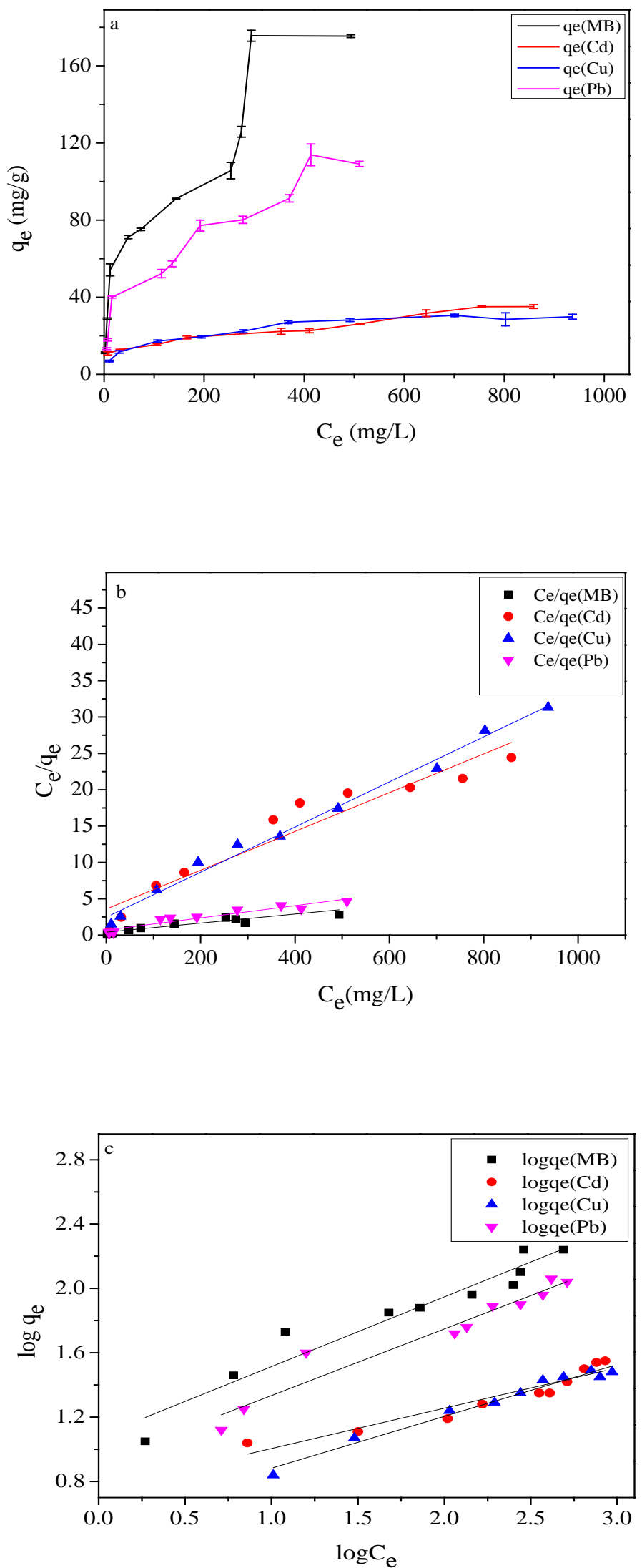
Fig. 9 Effect of initial concentration on heavy metals and MB (a), Langmuir isotherm model (b) and Freudlich isotherm model (c) on heavy metals and MB adsorption by MPS.
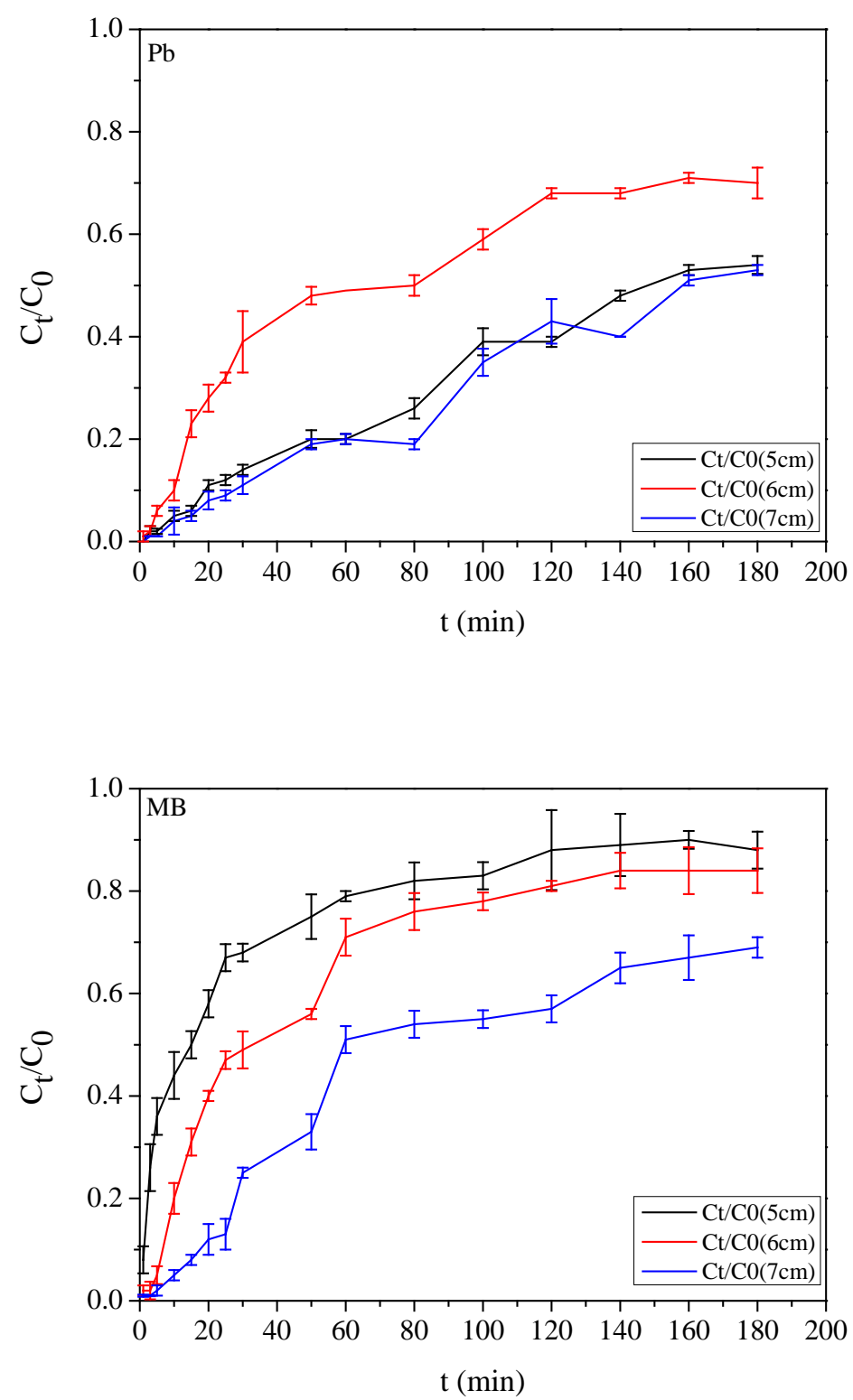

Fig. 10 Breakthrough curves of $\mathrm{Pb}^{2+}$ and $\mathrm{MB}$ with different bed heights (bed height: $5 \mathrm{~cm}, 6 \mathrm{~cm}, 7$ $\mathrm{cm}$; initial concentration: $200 \mathrm{mg} / \mathrm{L}$; room temperature; $\mathrm{pH}$ : $\mathrm{Pb}-5, \mathrm{MB}-6$; flow rate: $3.8 \mathrm{ml} / \mathrm{min}$ ) 


\section{Table captions:}

Table 1 Effect of the concentration of citric acid, reaction time and temperature on citric acid (CA) and peach stone (PS) reaction.

Table 2 The elemental analysis results of PS and MPS

Table 3 The BET surface area and pore volume of PS and MPS

Table 4 Kinetic parameters for $\mathrm{MB}, \mathrm{Cd}, \mathrm{Cu}, \mathrm{Pb}$ adsorption on M-PS

Table 5 Parameters of Langmuir and Freundlich isotherm

Table 1 Effect of the concentration of citric acid, reaction time and temperature on citric acid (CA) and peach stone (PS) reaction.

(a)

\begin{tabular}{lcccc}
\hline Adsorbent & $\begin{array}{c}\text { Reaction } \\
\text { time }(\mathrm{h})\end{array}$ & $\begin{array}{c}\text { Reaction } \\
\text { temperature }\left({ }^{\circ} \mathrm{C}\right)\end{array}$ & $\begin{array}{c}\mathrm{CA} \\
\text { concentration }(\mathrm{mol} / \mathrm{L})\end{array}$ & $\begin{array}{c}\mathrm{COOH} \\
(\mathrm{mol} / \mathrm{g})\end{array}$ \\
\hline PS & - & - & - & 0.000589 \\
MPS & & 0.2 & 0.00184 \\
MPS & 4 & 0.4 & 0.00242 \\
MPS & 120 & 0.6 & 0.00386 \\
MPS & & 0.8 & 0.00521 \\
MPS & & 1 & 0.00505 \\
\hline
\end{tabular}

(b)

\begin{tabular}{lcccc}
\hline Adsorbent & $\begin{array}{c}\text { Reaction } \\
\text { time }(\mathrm{h})\end{array}$ & $\begin{array}{c}\text { Reaction } \\
\text { temperature }\left({ }^{\circ} \mathrm{C}\right)\end{array}$ & $\begin{array}{c}\mathrm{CA} \\
\text { concentration }(\mathrm{mol} / \mathrm{L})\end{array}$ & $\begin{array}{c}\mathrm{COOH} \\
(\mathrm{mol} / \mathrm{g})\end{array}$ \\
\hline MPS & 1 & & & 0.00356 \\
MPS & 1.5 & & 0.8 & 0.00386 \\
MPS & 2 & 120 & 0.00461
\end{tabular}


MPS

MPS

(c)

\begin{tabular}{lcccc}
\hline Adsorbent & $\begin{array}{c}\text { Reaction } \\
\text { time (h) }\end{array}$ & $\begin{array}{c}\text { Reaction } \\
\text { temperature }\left({ }^{\circ} \mathrm{C}\right)\end{array}$ & $\begin{array}{c}\text { CA } \\
\text { concentration }(\mathrm{mol} / \mathrm{L})\end{array}$ & $\begin{array}{c}\mathrm{COOH} \\
(\mathrm{mol} / \mathrm{g})\end{array}$ \\
\hline MPS & 100 & 0.00477 \\
MPS & 110 & 0.8 & 0.00469 \\
MPS & 4 & 120 & & 0.00544 \\
MPS & 130 & & 0.00406 \\
MPS & 140 & 0.00398 \\
MPS & 150 & 0.00277 \\
\hline
\end{tabular}

Table 2 The elemental analysis results of PS and MPS

\begin{tabular}{lccccc}
\hline & $\mathrm{C}(\%)$ & $\mathrm{O}(\%)$ & $\mathrm{H}(\%)$ & $\mathrm{N}(\%)$ & $\mathrm{O} / \mathrm{C}(\mathrm{mol} / \mathrm{mol})$ \\
\hline PS & 48.13 & 45.64 & 6.201 & 0.031 & 0.7112 \\
MPS & 47.51 & 46.80 & 5.677 & 0.014 & 0.7388 \\
\hline
\end{tabular}

Table 3 The BET surface area and pore volume of PS and MPS

\begin{tabular}{lcc}
\hline & BET surface area $\left(\mathrm{m}^{2} / \mathrm{g}\right)$ & pore volume $\left(\mathrm{dm}^{3} / \mathrm{g}\right)$ \\
\hline PS & 0.330 & 3.675 \\
MPS & 0.0296 & 2.710 \\
\hline
\end{tabular}

Table 4 Kinetic parameters for MB, Cd, Cu, Pb adsorption on M-PS 


\begin{tabular}{lllll}
\hline & $\mathrm{MB}$ & $\mathrm{Cd}$ & $\mathrm{Cu}$ & $\mathrm{Pb}$ \\
\hline Pseudo-second-order kinetic model & & & & \\
$k\left(\mathrm{~g}_{\mathrm{mg}} \mathrm{mg}^{-1} \mathrm{~min}^{-1}\right)$ & 0.0003683 & 0.003792 & 0.006864 & 0.0005474 \\
$q_{e}(\mathrm{mg} / \mathrm{g})$ & 52.11 & 16.24 & 12.07 & 42.74 \\
$R^{2}$ & & & & \\
intra-particle diffusion kinetic model & & 0.9983 & 0.9843 & 0.9991 \\
$k_{p}\left(\mathrm{mg} . \mathrm{h}^{0.5} \cdot \mathrm{g}^{-1}\right)$ & 6.9996 & & & \\
$\mathrm{C}$ & & 4.024 & 0.5592 & 1.995 \\
$R^{2}$ & 16.84 & -5.330 & 4.924 & 24.59 \\
\hline
\end{tabular}

Table 5 Parameters of Langmuir and Freundlich isotherm

\begin{tabular}{lllll}
\hline & $\mathrm{MB}$ & $\mathrm{Cd}$ & $\mathrm{Cu}$ & $\mathrm{Pb}$ \\
\hline Langmuir model & & & & \\
$q_{\text {max }}\left(\mathrm{mg} \cdot \mathrm{g}^{-1}\right)$ & 178.25 & 37.48 & 32.22 & 118.76 \\
$K_{f}(\mathrm{~L} / \mathrm{mg})$ & 69.84 & 136.1 & 79.10 & 81.41 \\
$\mathrm{R}^{2}$ & & & & \\
Freundlich model & 0.8705 & 0.9133 & 0.9893 & 0.9161 \\
$K_{f}(\mathrm{mg} / \mathrm{g})$ & 12.05 & & & 8.321 \\
$\mathrm{n}$ & & 5.682 & 31.83 & \\
$\mathrm{R}^{2}$ & 2.309 & 3.990 & 17.83 & 2.415 \\
\hline
\end{tabular}

